\title{
Incorporación al ISI de la Revista Chilena de Cirugía
}

\section{Revista Chilena de Cirugía. ISI Incorporation}

La información científica se difunde mediante canales exclusivos como son las revistas, herramientas válidas en la divulgación de conocimientos. Se debe la especial trascendencia a los efectos que causan en la salud de la comunidad. Sin embargo, muchos artículos de revistas científicas de países denominados periféricos tienen una citación menor al 2\% en comparación con las editadas en países desarrollados $^{l}$ : existe la opinión que la publicación en idioma diferente al inglés es la causa que constituye una barrera idiomática infranqueable ${ }^{2}$.

Para examinar la productividad y el impacto de una investigación se crearon diferentes indicadores bibliométricos o de indización, muchos de los cuales son poco conocidos ${ }^{1}$. Uno de esos indicadores consiste en su inclusión en bases de datos como el Science Citation Index (SCI), posible de consultar on line a través del servicio WEB of Science (WOS) y que permite identificar los artículos más frecuentemente citados y quién lo hizo.

Adjudicado inicialmente a Eugene Garfield, introductor del SCI como instrumento de recuperación de la información y publicado por el Journal Citation Reports (JCR), es por propia definición un índice calendario-anual de la literatura científica existente en esa base de datos perteneciente al Instituto de Información Científica (Institute for Scientific Information-ISI). Este instituto, fundado en 1960 por Garfield y posteriormente adquirido por Thomson Scientific \& Healthcare en 1992, es frecuentemente conocido como Thomson ISI y ofrece servicios de bibliografia.

La mencionada base de datos, si bien detalla como fuentes de artículos 613 revistas consultadas desde 1964 hasta alcanzar a las 15.721 en 2005, no cubre la totalidad de las publicaciones mundiales y por lo tanto, es excesivamente selectiva. Su principal valor, según Garfield, reside en el manejo primario de colecciones de revistas por parte de bibliotecas y permitir así una mejor relación costo/beneficio para proponer suscripciones.

La inclusión de la Revista Chilena de Cirugía en esta exclusiva base de datos es una excelente noticia ya que permite reconocer, en forma válida, la calidad del contenido de los diferentes artículos allí publicados en idioma español. En forma similar a lo logrado a fines del año 2006 con su inclusión en la base de datos $S c i E L O^{3}$, esta nueva inserción en bases mundiales jerarquizadas, da la razón a la necesidad de consultar esta revista debido a la calidad de su contenido en el ámbito de la cirugía.

Facilitará, de esta manera, su admisión en el contexto científico mundial y destacará la trascendencia de las investigaciones desarrolladas tanto en el ámbito local como en el regional. Se continúa, de esta forma, por la senda recientemente iniciada enfrentando nuevos retos que despierten ilusiones no exclusivamente nacionales, por ser una distinguida representante del mensaje quirúrgico sudamericano.

Dr. Eduardo B. Arribalzaga, MCSE MWAME

División Cirugía Torácica Hospital de Clínicas, Buenos Aires, Argentina Editor Revista Argentina de Cirugía

\section{Referencias}

1. Arribalzaga EB. El factor de impacto o el impacto de factores. Rev Chil Cir 2005; 57: 269-274.
2. Arribalzaga EB. Reflexiones sobre el factor de impacto. Arch Bronconeumol 2006; 42: 310.

3. Manterola C. Revista Chilena de Cirugía indexada en SciELO. Lo relevante y lo que viene por delante. Rev Chil Cir 2007; 59: 1-2.

Correspondencia: Dr. Eduardo B. Arribalzaga

Avenida Rivadavia 4282 Piso $4^{\circ}$ Depto. H, Buenos Aires, CP 1205, Argentina.

E-mail: piedralta@hotmail.com 